\title{
Refractory Ascites
}

\author{
Andrés Cárdenas Vicente Arroyo \\ Liver Unit, Institute of Digestive Diseases, Hospital Clinic, University of Barcelona, Barcelona, Spain
}

\section{Key Words}

Cirrhosis · Ascites - Transjugular intrahepatic portosystemic shunt · Paracentesis · Liver transplantation

\begin{abstract}
Patients with cirrhosis have significant abnormalities in their fluid and electrolyte balance; this is manifested mainly by the development of ascites and edema. Ascites is the most common complication of patients with cirrhosis and its development constitutes the first and most important manifestation of the disease. With disease progression, patients with advanced cirrhosis and severe urinary sodium retention develop refractory ascites, a condition in which patients do not respond to diuretics or develop severe side effects to these that preclude their use. This condition occurs in $5-10 \%$ of cases admitted to the hospital for treatment of ascites. Approximately half of these patients will die within 1 year if not transplanted; therefore, the best therapy is liver transplantation in suitable candidates. During the last two decades, significant advances have been made in regard to pathogenesis and treatment of refractory ascites. The reintroduction of therapeutic paracentesis with plasma expansion in the 1980s was a milestone in the treatment of these patients. In addition, the introduction of transjugular intrahepatic portosystemic shunts as a therapy for refractory ascites has certainly provided a reasonable alternative for those patients with preserved liver function and unwilling to undergo several taps per month. This article will discuss the pathophysiology, clinical features and therapy of refractory ascites in cirrhosis.
\end{abstract}

Copyright (C) 2005 S. Karger AG, Basel
(C) 2005 S. Karger AG, Basel 0257-2753/05/0231-0030\$22.00/0

Fax +4161306 1234 E-Mail karger@karger.ch www.karger.com www.karger.com/ddi

\section{Introduction}

Patients with cirrhosis may develop significant complications of renal function manifested by sodium retention, water retention and renal vasoconstriction. These are responsible for fluid accumulation in the form of ascites, dilutional hyponatremia and hepatorenal syndrome, respectively. Ascites is the most common complication of cirrhosis and results in poor quality of life, increased risk of infections, renal failure and mortality. Nearly $60 \%$ of patients with compensated cirrhosis develop ascites within 10 years of disease onset [1]. The development of ascites in cirrhosis is a poor prognostic feature: it has been estimated that approximately $50 \%$ of these patients will die in approximately 2 years without liver transplantation [2]. Therefore the presence of ascites in a cirrhotic patient is an indication for liver transplantation. Refractory ascites is an infrequent condition in cirrhosis as only $5-10 \%$ of cirrhotic patients admitted to hospital for large ascites do not respond to diuretics or present complications that preclude the administration of adequate doses of these drugs [3]. Patients with refractory ascites usually have advanced liver disease, severe urinary sodium retention and therefore a bad prognosis, with a $50 \%$ chance of dying within 1 year if not transplanted [2].

\section{Pathophysiology of Ascites}

Ascites develops when there is severe sinusoidal portal hypertension and an increase in splanchnic production of lymph that overcomes the lymphatic return. The accumulation of fluid in the abdominal cavity is the result of the leakage of this excess of lymph from the hepatic and 


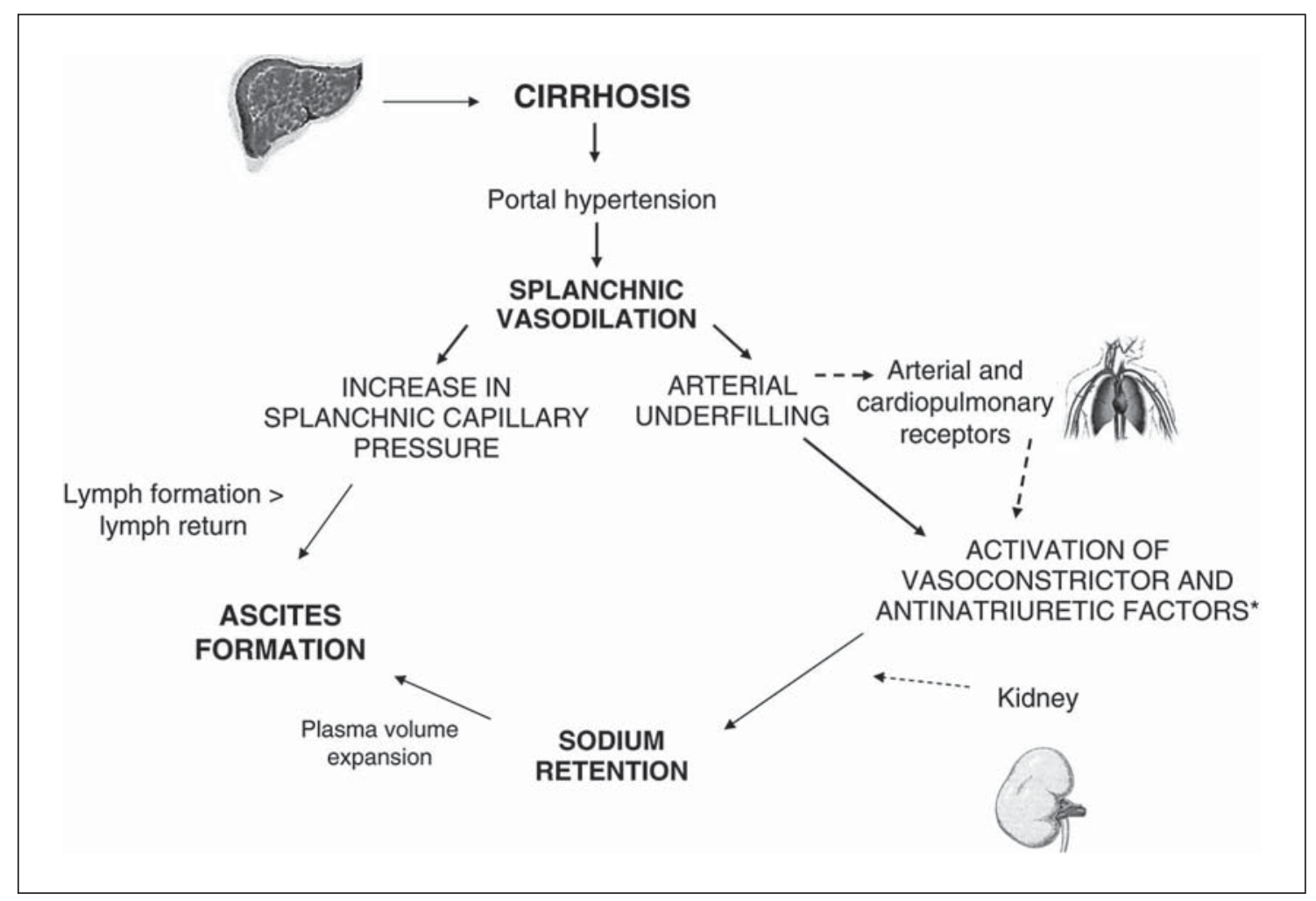

Fig. 1. Pathogenesis of ascites formation according to the forward theory.

splanchnic interstitial space into the intraperitoneal space. The high lymph production in the splanchnic capillaries is secondary to an increase in both the hydrostatic pressure and the filtration coefficient in the splanchnic microcirculation $[4,5]$. There is evidence that this is predominantly due to increased blood flow into this vascular territory secondary to a splanchnic arterial vasodilation that triggers vasoactive substances that retain sodium and water $[5,6]$. The marked splanchnic vasodilation contributes to portal hypertension by increasing portal venous inflow and inducing changes in the microcirculation that predispose to increased filtration of plasma. Several vasodilator factors are responsible for this vasodilation. Most of the available data suggest that nitric oxide, a potent arterial vasodilator, may be the main factor involved [6]. Ongoing replenishment of the intravascular space by means of sodium and water retention is what perpetuates this pathological state. The formation of ascites in cirrhosis is the final consequence of a combination of abnormalities in the splanchnic and systemic circulation as well as renal function abnormalities that bring about the accumulation of fluid in the peritoneal cavity.
Aside from changes in splanchnic hemodynamics, cirrhotic patients with ascites develop a hyperdynamic state characterized by reduced systemic vascular resistance and arterial pressure, increased cardiac output, and activation of vasoconstrictor and antinatriuretic systems (renin-angiotensin and sympathetic nervous systems and antidiuretic hormone or arginine vasopressin). By decreasing the effective arterial blood volume splanchnic vasodilation unloads the central baroreceptors, thereby triggering the activation of these systems, which play a fundamental role in the development of ascites (fig. 1).

\section{Renal Functional Abnormalities}

Sodium retention is a necessary condition for ascites formation. Sodium is reabsorbed in excess with water by the renal tubules and this fluid accumulates in the abdominal cavity as ascites. Sodium retention is chronologically the initial renal function abnormality in cirrhosis (fig. 2) [7]. In advanced cirrhosis, sodium retention further leads to the expansion of extracellular fluid volume and to an increased amount of fluid in the interstitial tissue. The pathogenesis is explained by an abnormally 


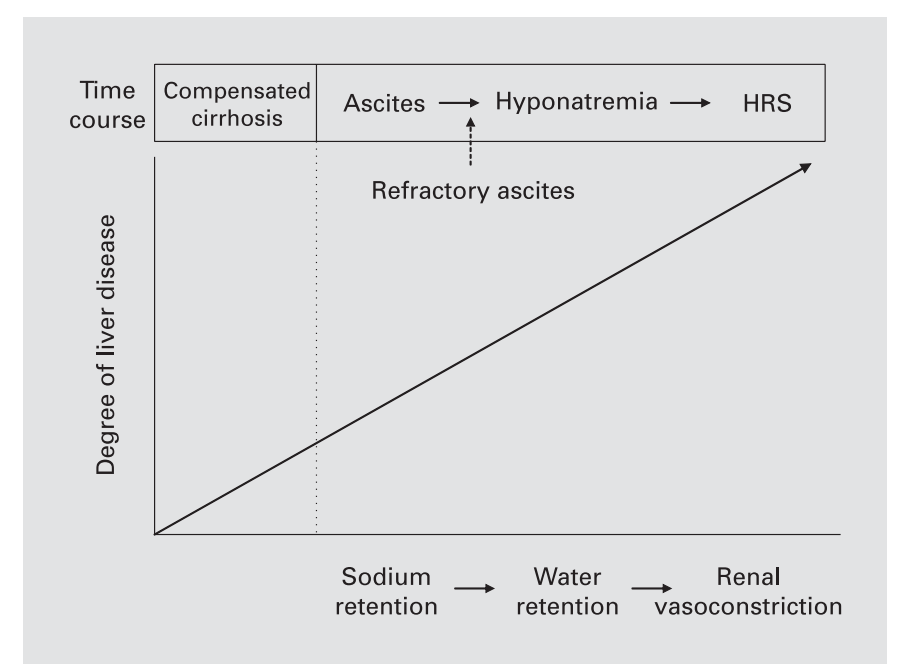

Fig. 2. Temporal relationship of the development of renal function abnormalities in cirrhosis. Refractory ascites occurs after initial ascites formation, is associated with intense sodium retention (urine sodium $<10 \mathrm{mEq} / \mathrm{l}$ ) and usually precedes dilutional hyponatremia and hepatorenal syndrome.

increased reabsorption of sodium in the renal tubules (proximal and distal) because it occurs in the setting of a normal filtered sodium load [5]. The three major hormones acting on the renal tubules to retain sodium are aldosterone, angiotensin and norepinephrine. Refractory ascites usually occurs when patients have advanced liver disease and exhibit very intense urinary sodium retention (urine sodium $<10 \mathrm{mEq} / \mathrm{l}$ ) (fig. 2). In a more advanced phase of the disease, patients develop severe impairment in the renal ability to excrete water, which results in dilutional hyponatremia and hypoosmolality. In the end stage of cirrhosis, patients develop intense renal vasoconstriction that causes a marked fall in renal perfusion and glomerular filtration rate. This condition, known as hepatorenal syndrome (HRS), may follow a rapidly progressive course (type $1 \mathrm{HRS}$ ) or a steady course (type 2 HRS) [8]. Most patients with refractory ascites have type 2 HRS.

\section{Theories of Ascites Formation}

All theories involve sodium and water retention either as a primary event or due to changes in systemic hemodynamics. The overfill theory suggests that in advanced cirrhosis a 'sodium-retaining signal' is produced with subsequent sodium and water retention in the renal tubules
[9]. The existence of this 'sodium-retention signal' has been suggested by two mechanisms: one is the presence of a 'hepatorenal reflex' arising from intrahepatic baroreceptors and the other is the decreased clearance of a sodium-retaining substance. To date, there is no hard evidence to fully support this concept. Another argument against this theory relies on the fact that these patients have an underfilled rather than overfilled arterial vascular bed.

The forward theory considers that the first event in ascites formation is sinusoidal portal hypertension, which causes splanchnic arteriolar vasodilation (fig. 1) [10]. Vasodilation in the splanchnic circulation simultaneously produce systemic arterial vascular underfilling and a 'forward' increase in the splanchnic capillary pressure and filtration coefficient. In patients with compensated cirrhosis, the degree of portal hypertension and splanchnic arterial vasodilation is moderate. Arterial underfilling is compensated by an increase in plasma volume and cardiac output. In these patients, the lymphatic system is able to return the moderate increase in lymph produced to the systemic circulation, thus preventing leakage of fluid into the abdominal cavity. As cirrhosis progresses, portal hypertension and decreased splanchnic vascular resistance turn progressively worse and a critical point is reached in which the consequences of this intense splanchnic arterial vasodilation cannot be compensated for by increasing lymph return, plasma volume, and cardiac output. The maintenance of arterial pressure then requires persistent activation of the renin-angiotensin-aldosterone system, the sympathetic nervous system, and the antidiuretic hormone, which produce continuous sodium and water retention. The retained fluid is, however, ineffective in refilling the dilated arterial vascular bed because it escapes from the intravascular compartment, due to an imbalance between the excessive lymph production and the ability of the lymphatic system to return it to the systemic circulation. The final consequence of both disorders is persistent renal sodium and water retention with ongoing leakage of fluid into the abdominal cavity and the formation of ascites.

\section{Definition and Diagnostic Criteria of Refractory Ascites}

The generally accepted definition and diagnostic criteria of refractory ascites are those proposed by the International Ascites Club in a consensus conference and published in 1996 and recently revised in 2003 [3, 11]. In 
refractory ascites, a significant increase in sodium excretion cannot be achieved either because patients do not respond to high doses of diuretics (spironolactone $400 \mathrm{mg}$ / day and furosemide $160 \mathrm{mg}$ /day) or because they develop side effects such as hyperkalemia, hyponatremia, hepatic encephalopathy, or renal failure that preclude their use.

Refractory ascites was initially defined as 'ascites that cannot be mobilized or the early recurrence of which (i.e., after therapeutic paracentesis) cannot be satisfactorily prevented by medical therapy'. Refractory ascites occurs in $5-10 \%$ of cirrhotic patients admitted for large or tense ascites [3]. The term 'refractory ascites' includes the following two subtypes: (1) diuretic-resistant ascites: ascites that cannot be mobilized or the early recurrence of which cannot be prevented because of a lack of response to dietary sodium restriction and intensive diuretic therapy. This type of refractory ascites is indicative of progression of the liver disease and is not reversible except in patients with alcoholic hepatitis. The vast majority of patients have a urinary sodium $<10 \mathrm{mEq} / \mathrm{l}$. (2) Diuretic-intractable ascites: ascites that cannot be mobilized or the early recurrence of which cannot be prevented because of the development of diuretic-induced complications that preclude the use of an effective diuretic dosage. The diagnostic criteria established and recently reviewed are described in table 1.

\section{Prognosis}

Patients with refractory ascites constitute a subset of patients with ascites with a particularly poor prognosis, the estimated 1-year survival probability is only $50 \%$ [2, 11-13]. In a recent study at a large center, 75 patients with refractory ascites as defined by the International Ascites Club were followed for $18 \pm 13$ months [13]. The 1 -year probability of survival was $52 \%$ (fig. 3 ). In this study, older age $(>60)$, hepatocellular carcinoma, and diabetes (but not Child-Pugh at entry) were independent predictive factors of poor survival.

\section{Management}

The first and most important aspect in the management of all patients with cirrhosis and ascites is an evaluation for liver transplantation [11]. Early referral is recommended due to the short survival of some patients once they develop ascites. In clinical practice, the easiest way of identifying patients that need priority liver trans-

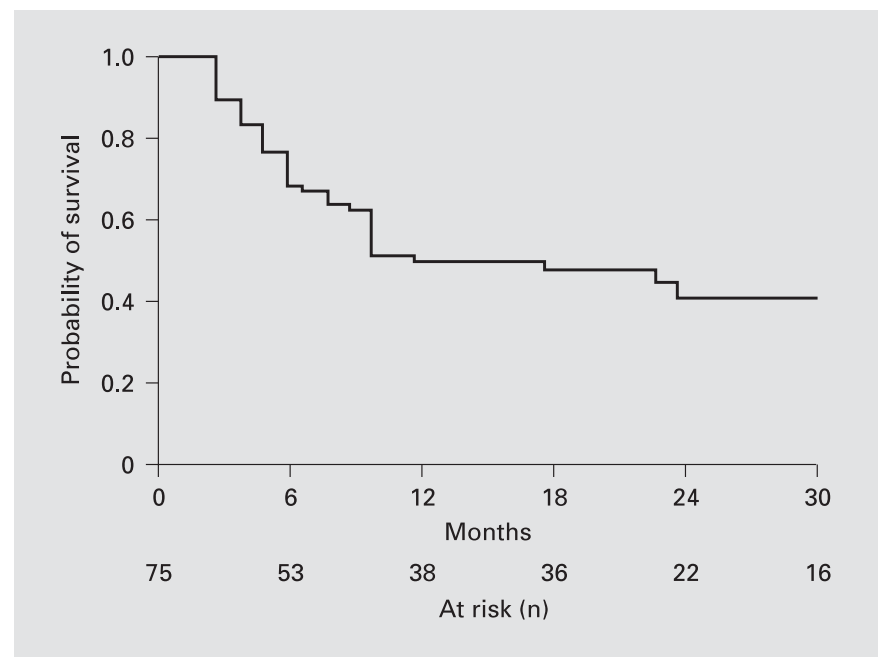

Fig. 3. Probability of survival in patients with cirrhosis and refractory ascites. Reproduced from Moreau et al. [13], with permission.

Table 1. Definition and diagnostic criteria for refractory ascites in cirrhosis

Diuretic-resistant ascites: Ascites that cannot be mobilized or the early recurrence of which cannot be prevented because of a lack of response to sodium restriction and diuretic treatment.

Diuretic-intractable ascites: Ascites that cannot be mobilized or the early recurrence of which cannot be prevented because of the development of diuretic-induced complications that preclude the use of an effective diuretic dosage.

Requisites

1 Treatment duration: Patients must be on intensive diuretic therapy (spironolactone $400 \mathrm{mg}$ /day and furosemide $160 \mathrm{mg} /$ day) for at least 1 week and on a salt-restricted diet of less than $90 \mathrm{mmol} /$ day.

2 Lack of response: Mean weight loss of $<0.8 \mathrm{~kg}$ over 4 days and urinary sodium output less than the sodium intake.

3 Early ascites recurrence: Reappearance of grade 2 or 3 ascites within 4 weeks of initial mobilization.

4 Diuretic-induced complications: Diuretic-induced hepatic encephalopathy is the development of encephalopathy in the absence of any other precipitating factor. Diuretic-induced renal impairment is an increase of serum creatinine by $>100 \%$ to a value $>2 \mathrm{mg} / \mathrm{dl}$ in patients with ascites responding to treatment. Diuretic-induced hyponatremia is defined as a decrease of serum sodium by $>10 \mathrm{mmol} / \mathrm{l}$ to a serum sodium of $<125 \mathrm{mmol} / \mathrm{l}$. Diuretic-induced hypo- or hyperkalemia is defined as a change in serum potassium to $<3 \mathrm{mmol} / \mathrm{l}$ or $>6 \mathrm{mmol} / \mathrm{l}$ despite appropriate measures.

Modified with permission from Moore et al. [11]. 
plantation is to recognize those with severe renal functional abnormalities, such as refractory ascites or HRS and those with bacterial infections such as spontaneous bacterial peritonitis. However, patients with these conditions have a short survival and may die while awaiting for liver transplantation. An evaluation by a nutritionist is recommended for appropriate education regarding appropriate caloric and salt intake. A low-sodium diet of $70-90 \mathrm{mmol} /$ day is one of the mainstays of management. Improvement of the nutritional status is of key importance given that cirrhotics with advanced disease have decreased intake of nutrients, decreased absorption of nutrients, increased energy expenditure and altered fuel metabolism with an accelerated starvation metabolism. Cirrhotic patients with refractory ascites that undergo a transjugular portosystemic shunt (TIPS) for therapy of ascites significantly improve their nutritional status as measured by resting energy expenditure, total body nitrogen, body fat and food intake [14].

\section{Therapy}

Treatment options after considering liver transplantation include repeated large-volume paracentesis plus plasma expansion or TIPS. Peritoneo-venous shunts, although very effective, were abandoned due to significant complications when compared to paracentesis [15].

\section{Therapeutic Paracentesis}

This treatment has been used to manage patients with ascites since the time of the ancient Greeks. Interest in paracentesis decreased in the 1950s when diuretics started to be used to treat patients with cirrhosis and ascites. Still, some patients were intolerant to diuretics or just did not respond to them. Therefore in the mid-1980s the interest for this procedure was renewed as a treatment for patients with large and refractory ascites and its safety was clearly demonstrated in our Liver Unit [16]. Currently, therapeutic paracentesis is performed as the initial treatment for large and refractory ascites. Complete removal of ascites in one tap has been shown to be quick, effective and associated with a lower number of complications than conventional diuretic therapy [16]. Following paracentesis, plasma expansion with albumin $(8 \mathrm{~g} / \mathrm{l}$ of ascites removed) is recommended in all patients in order to prevent the post-paracentesis circulatory dysfunction $[16,17]$. Albumin has proven superior to dextran-70, polygeline, and saline for large-volume paracentesis greater than 5 liters, but randomized studies have not shown any significant difference in survival between patients treated with albumin and those treated with other plasma expanders, likely due to a low sample size [16, 18-20]. The use of albumin is controversial because it has not shown improvement in survival and has an elevated cost; however, it has a superior protective effect on the circulatory system compared with other expanders and therefore it is the preferred plasma expander in patients treated with large-volume paracentesis [16-18]. When less than 5 liters are removed, an alternate synthetic plasma expander may be used $[19,20]$. On average, patients with refractory ascites require a tap every 2-4 weeks, and the majority may be treated as outpatients, making this option easy to perform and cost-saving; therefore it is considered the first-line treatment for refractory ascites.

\section{Transjugular Intrahepatic Portosystemic Shunt}

TIPS was developed over 2 decades ago as a treatment and alternative to shunt surgery for variceal bleeding [21]. Initial experience demonstrated that patients that received TIPS had good control of their ascites. This observation, in addition to the fact that ascites formation occurs when portal pressure is $>12 \mathrm{~mm} \mathrm{Hg}$, led to the rationale of applying this interventional radiology procedure as therapy for ascites. TIPS is a nonsurgical method of portal decompression that acts as a side-to-side portocaval shunt and reduces portal pressure, ascites and diuretic requirements in these patients [21,21]. Over the past decade several retrospective, prospective and randomized controlled studies (RCT) evaluating the effects of TIPS in refractory ascites have been published [8, 23-47]. The initial criteria for inclusion were surprisingly very homogeneous. In total more than 500 patients have been treated with TIPS for refractory ascites as reported in the literature and in many centers this procedure is routinely used as therapy for refractory ascites. In the initial retrospective studies, the response rates ranged from to 22$46 \%$; however, the mortality rate at 12 months ranged from 36 to $67 \%[8,23,35,37]$. The response rates in RCT were higher, with a complete response following TIPS observed in $51-79 \%$ cases vs. $3-24 \%$ in the paracentesis groups [44-47]. In all studies, ascites resolution was rapidly achieved with TIPS and, compared with patients receiving therapeutic paracentesis, a significant difference was observed in the amount of taps these patients with TIPS required. In addition, it has been reported that the quality of life improves after TIPS [48]. The main disadvantage with TIPS is frequent obstruction of the prosthesis ( $70 \%$ in 1 year) [21], which precipitates rapid reaccumulation of ascites in some patients; however, newer 
Table 2. Randomized controlled studies comparing TIPS vs. large-volume paracentesis with plasma expansion in the treatment of refractory ascites

\begin{tabular}{|c|c|c|c|c|c|c|c|c|}
\hline \multirow[t]{2}{*}{ Reference } & \multicolumn{2}{|c|}{$\begin{array}{l}\text { Number of } \\
\text { patients }\end{array}$} & \multicolumn{2}{|c|}{$\begin{array}{l}\text { Ascites improved } \\
\%\end{array}$} & \multicolumn{2}{|c|}{$\begin{array}{l}\text { Survival }{ }^{1} \\
\%\end{array}$} & \multicolumn{2}{|c|}{$\begin{array}{l}\text { New or severe } \\
\text { encephalopathy, } \%\end{array}$} \\
\hline & TIPS & LVP & TIPS & LVP & TIPS & LVP & TIPS & LVP \\
\hline Lebrec et al. [43] & 13 & 12 & 38 & 0 & 29 & 60 & 15 & 6 \\
\hline Rossle et al. [45] & 29 & 31 & $84^{2}$ & 43 & 58 & 32 & 23 & 13 \\
\hline Gines et al. [44] & 35 & 35 & $51^{2}$ & 17 & 26 & 30 & 60 & 34 \\
\hline Sanyal et al. [46] & 52 & 57 & $58^{2}$ & 16 & 35 & 33 & 38 & 21 \\
\hline Salerno et al. [47] & 33 & 33 & $79^{2,3}$ & 42 & $59^{2}$ & 29 & 61 & 39 \\
\hline
\end{tabular}

\footnotetext{
Reproduced with permission from Boyer and Haskal [21].

${ }^{1}$ Transplant-free survival after 2 years is for the studies of Gines et al. [44] and Sanyal et al. [46].

${ }^{2}$ Significant difference between two groups.

${ }^{3}$ End point was failure, which was defined as the need for at least four large-volume paracenteses for recurrent ascites.
}

polytetrafluoroethylene-coated prostheses improve TIPS patency and decrease the number of clinical relapses and reinterventions without increasing the risk of encephalopathy [22]. Other major side effects associated with TIPS include a $20-30 \%$ chance of hepatic encephalopathy, congestive heart failure, hemolytic anemia and impairment in liver function [21].

\section{Selection of Patients for TIPS}

The indications and contraindications of placing TIPS have been reviewed recently [21] and for the most part in patients with refractory ascites, advanced age $(>75)$, congestive heart failure, unrelieved biliary obstruction, sepsis, severe coagulopathy (INR $>5$ ), grade 3 or 4 (West Haven criteria) hepatic encephalopathy and Child score $>12$ are considered to be contraindications. Patients with preserved liver function in general do well clinically after TIPS; but those with severe liver failure often continue to deteriorate and may die after TIPS. Since TIPS does not treat cirrhosis, it does not seem to improve survival in those patients with a Child score $>12$ [11]. The prognosis of patients receiving TIPS seems to be related to the severity of the underlying liver disease [21, 49]. In fact, mortality rates are the same for patients with similar Child-Pugh scores irrespective of the indication for the procedure [49]. Therefore, to better determine which patients are at risk of doing poorly after a TIPS, two prognostic models have been proposed [49, 50]. The most utilized model is that from which the model of end-stage liver disease (MELD) was created [50]. In this model, INR, total serum bilirubin level, serum creatinine level, and etiology of cirrhosis accurately predicted survival (particularly at 3 months) after TIPS was placed. In the other model, variables including bilirubin level $>3.0 \mathrm{mg} /$ $\mathrm{dl}$, alanine aminotransferase level $>100$ IU/l, pre-TIPS encephalopathy, and urgency of TIPS were independent predictors of survival [49]. Neither of these two models has been specifically validated for patients with refractory ascites. Given these results, it seems prudent to withhold TIPS in those with serum bilirubin $>5 \mathrm{mg} / \mathrm{dl}$, an INR $>3$, and a Child score $>12$. Nonetheless these are far from being strict criteria and the recommendation to perform TIPS has to be individualized.

\section{TIPS versus Paracentesis in Refractory Ascites}

Five RCT have been performed to determine if TIPS is superior to paracentesis in patients with refractory ascites These trials of TIPS vs. repeated paracentesis show that TIPS is associated with a lower rate of ascites recurrence, but a higher rate of hepatic encephalopathy [4347]. The data from these studies are summarized in table 2 . In the TIPS group, $62 \pm 19.2 \%$ showed improvement in ascites vs. $23.6 \pm 18.5 \%$ in the paracentesis group. There is also conflicting evidence as regards survival because some studies have shown a survival benefit with TIPS whereas others have not shown any difference in survival [43-47]. The transplant-free survival rate at 2 years in two studies was similar, ranging from 26 to $35 \%$ for the TIPS group to $30-33 \%$ in the paracentesis group $[44,46]$. Discrepancies within the other studies may be 


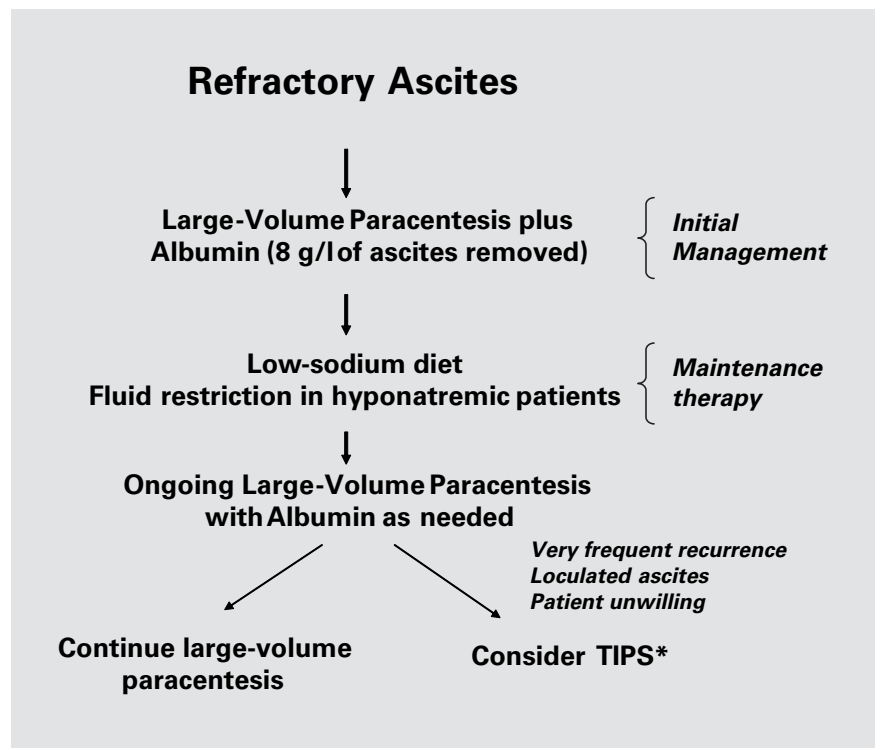

Fig. 4. Proposed treatment strategy for patients with refractory ascites. ${ }^{*}$ Consider use of TIPS in patients with preserved hepatic function, no hepatic encephalopathy, no cardiac disease compartmentalized fluid, and those having repeated paracentesis more than 3-4 times per month.

attributed to the fact that TIPS was performed in the early to mid 1990s at which time the experience with TIPS was scarce and there were no predictive factors of poor outcome $[43,45]$. In the most recent study, survival was significantly better, but again this could be related to the fact that there was more experience and familiarity with TIPS, and that patients were carefully selected avoiding the inclusion of older patients, grade 2 hepatic encephalopathy, a Child score $>11$, and bilirubin level $>6$ [47]. A very important aspect to consider when treating patients is cost. The price of treating patients with refractory ascites with TIPS is much higher than the cost of repeated paracentesis plus albumin [44]. Given these conflicting data, it is difficult to recommend strict guidelines; nonetheless it appears that large-volume paracentesis is the initial treatment of choice because of its wider applicability, lower cost and lesser side effects compared with TIPS. Nonetheless, placement of TIPS should be considered in all patients with refractory ascites and only after evaluating the patient's preference, clinical status, Child score, bilirubin levels, cardiac function, and INR should the decision of placing a TIPS be made. TIPS placement must be evaluated on a case-by-case basis and should probably be reserved for patients with preserved liver function (bilirubin $<5$, INR $<3$, Child score $<12$ ), without hepatic encephalopathy or cardiopulmonary disease, with loculated fluid, those requiring more than 3-4 taps per months or those unwilling to undergo repeated paracentesis. Figure 4 outlines a proposed therapeutic strategy for the treatment of refractory ascites.

\section{Summary}

Patients with cirrhosis and refractory ascites have a poor prognosis with a 1-year probability of survival of $50 \%$. These patients must be considered for liver transplantation. However, as the demand for liver transplantation rises, patients will likely spend longer times on a waiting list with a further risk of more decompensation and therefore all attempts at controlling ascites in these patients should be made. It seems that therapeutic paracentesis is the initial treatment of choice given its low cost, wide applicability, and low rate of side effects. In selected candidates with preserved liver function or those that require many taps per month, TIPS is a very reasonable option and its placement undoubtedly reduces ascites and likely improves the quality of life of these patients. The survival benefit of both procedures is similar; however, if patients are very carefully selected, TIPS seems to provide a better survival. 


\section{References}

1 Ginès P, Quintero E, Arroyo V, et al: Compensated cirrhosis: Natural history and prognostic factors. Hepatology 1987; 7:122-128.

2 Ginès P, Fernández-Esparrach G: Prognosis of ascites; in Arroyo V, Ginès P, Rodés J, Schrier RW (eds): Ascites and Renal Dysfunction in Liver Disease. Malden, Blackwell Science, 1999, pp 431-441.

-3 Arroyo V, Ginès P, Gerbes A, et al: Definition and diagnostic criteria of refractory ascites and hepatorenal syndrome in cirrhosis. Hepatology 1996;23:164-176.

4 Harris NR, Granger DN: Alterations of hepatic and splanchnic microvascular exchange in cirrhosis: Local factors in the formation of ascites; in Arroyo V, Ginès P, Rodés J, Schrier RW (eds): Ascites and Renal Dysfunction in Liver Disease. Malden, Blackwell Science, 1999, pp 351-362.

-5 Cárdenas A, Arroyo V: Mechanisms of sodium and water retention in liver cirrhosis. Best Pract Res Clin Endocrinol Metab 2003;17: 607-622.

-6 Martin PY, Ginès P, Schrier RW: Nitric oxide as a mediator of hemodynamic abnormalities and sodium and water retention in cirrhosis. $\mathrm{N}$ Engl J Med 1998;339:533-541.

7 Levy M, Allotey JB: Temporal relationships between urinary salt retention and altered systemic hemodynamics in dogs with experimental cirrhosis. J Lab Clin Med 1978;92:560569.

-8 Rees CJ, Rose JD, Record CO, et al: Transjugular intrahepatic portosystemic shunt: A limited role in refractory ascites. Eur J Gastroenterol Hepatol 1997;9:969-973.

-9 Ming Z, Smyth DD, Lautt WW: Decreases in portal flow trigger a hepatorenal reflex to inhibit renal sodium and water excretion in rats: Role of adenosine. Hepatology 2002;35:167175.

10 Cárdenas A, Bataller R, Arroyo V: Mechanisms of ascites formation. Clin Liver Dis 2000;4:447-465.

11 Moore KP, Wong F, Ginès P, et al: The management of ascites in cirrhosis: Report on the consensus conference of the International Ascites Club. Hepatology 2003;38:258-266.

12 Salerno F, Borroni G, Moser P, et al: Survival and prognostic factors of cirrhotic patients with ascites: A study of 134 outpatients. Am J Gastroenterol 1993;88:514-519.

$\checkmark 13$ Moreau R, Delegue P, Pessione F, Hillaire S, Durand F, Lebrec D, Valla DC: Clinical characteristics and outcome of patients with cirrhosis and refractory ascites. Liver Int 2004; 24:457-464.

14 Allard JP, Chau J, Sandokji K, Blendis LM, Wong F: Effects of ascites resolution after successful TIPS on nutrition in cirrhotic patients with refractory ascites. Am J Gastroenterol 2001;96:2442-2447.
15 Gines P, Arroyo V, Vargas V, et al: Paracentesis with intravenous infusion of albumin as compared with peritoneovenous shunting in cirrhosis with refractory ascites. $\mathrm{N}$ Engl $\mathrm{J}$ Med 1991;325:829-835.

16 Gines P, Arroyo V, Quintero E, Planas R, Bory F, Cabrera J, Rimola A, Viver J, Camps J, Jimenez W, et al: Comparison of paracentesis and diuretics in the treatment of cirrhotics with tense ascites. Results of a randomized study. Gastroenterology 1987;93:234-241.

17 Ruiz-del-Arbol L, Monescillo A, Jiménez W, Garcia-Plaza A, Arroyo V, Rodés J: Paracentesis-induced circulatory dysfunction: Mechanism and effect on hepatic hemodynamics in cirrhosis. Gastroenterology 1997;113:579586.

18 Ginès $\mathrm{P}$, Cardenas, A, Arroyo V, Rodés J: Management of cirrhosis and ascites. N Engl J Med 2004;350:1646-1654.

19 Gines A, Fernandez-Esparrach G, Monescillo $\mathrm{A}$, et al: Randomized trial comparing albumin, dextran 70, and polygeline in cirrhotic patients with ascites treated by paracentesis. Gastroenterology 1996;111:1002-1010.

20 Sola-Vera J, Minana J, Ricart E, et al: Randomized trial comparing albumin and saline in the prevention of paracentesis-induced circulatory dysfunction in cirrhotic patients with ascites. Hepatology 2003;37:1147-1153.

21 Boyer TD, Haskal Z: The role of transjugular intrahepatic portosystemic shunt in the management of portal hypertension. Hepatology 2005;41:386-400.

22 Bureau C, Garcia-Pagan JC, Otal P, et al: Improved clinical outcome using polytetrafluoroethylene coated stents for TIPS: Results of a randomized study. Gastroenterology 2004; 126:469-475.

23 Williams DB, Waugh R, Selby W: Transjugular intrahepatic portosystemic shunt (TIPS) for the treatment of refractory ascites. Aust New Zealand J Med 1998;28:620-626.

24 Ochs A, Rossle M, Haag K, et al: The transjugular intrahepatic portosystemic stent-shunt procedure for refractory ascites. N Engl J Med 1995;332:1192-1197.

25 LeMoine O, Nevens F, Deviere J, et al: TIPS for refractory ascites. A Belgian two-center experience (abstract). Hepatology 1996; 24(suppl):445A.

26 Benner KG, Sahagun G, Saxon R, et al: What predicts survival and resolution of refractory ascites after TIPS? (abstract). Hepatology 1996;24(suppl):449A.

27 Hills C, Miller LS, Ter H, et al: Increased colloid pressure correlates with resolution of refractory ascites after transjugular intrahepatic portal-systemic shunt (TIPS) (abstract). Hepatology 1995;22(suppl):165A.
28 Peron JM, Rousseau H, Vinel JP, et al: TIPS in the treatment of refractory ascites: Results in 31 consecutive patients with cirrhosis (abstract). Gastroenterology 1995; 108(suppl): $1145 \mathrm{~A}$.

29 Sezai S, Kamisaka K, Hirano M: Effectiveness of transjugular intrahepatic shunt (TIPS) for refractory ascites (abstract). Hepatology 1995; 22(suppl):489A.

30 Thuluvath PJ, Mitchell S, Prescott C, Osterman F: TIPSS for refractory ascites and advanced cirrhosis (abstract). Hepatology 1995; 22(suppl):165A.

31 Shrestha R, McKinley C, Showalter R, et al: Transjugular intrahepatic portosystemic shunt (TIPS) for ascites: The prognostic and predictive value of quantitative liver function tests (abstract). Hepatology 1996;24:449A.

32 Wong F, Sniderman K, Liu P, et al: Transjugular intrahepatic portosystemic stent shunt: Effects on hemodynamics and sodium hemostasis in cirrhosis and refractory ascites. Ann Intern Med 1995;122:816-822.

33 Ferral H, Bjarnason H, Wegryn SA, et al: Refractory ascites. Early experience in treatment with transjugular intrahepatic portosystemic shunt. Radiology 1993;189:795- 801.

34 Nazarian GK, Bjarnason H, Dietz CA Jr, et al: Refractory ascites: Midterm results of treatment with a transjugular intrahepatic portosystemic shunt. Radiology 1997;205:173-180.

35 Forrest EH, Stanley AJ, Redhead DN, et al: Clinical response after transjugular intrahepatic portosystemic stent shunt insertion for refractory ascites in cirrhosis. Aliment Pharmacol Ther 1996;10:801-806.

36 Deschenes M, Dufresne MP, Bao B, et al: Predictors of clinical response to transjugular intrahepatic portosystemic shunt (TIPS) in cirrhotic patients with refractory ascites. Am J Gastroenterol 1999;94:1361-1365.

37 Trotter JF, Suhocki PV, Rockey DC: Transjugular intrahepatic portosystemic shunt (TIPS) in patients with refractory ascites: Effect of body weight and Child-Pugh score. Am J Gastroenterol 1998;93:1891-1894.

38 Somberg KA, Lake JR, Tomlanovich SJ, et al: Transjugular intrahepatic portosystemic shunts for refractory ascites: Assessment of clinical and hormonal response and renal function. Hepatology 1995;21:709-716.

39 Crenshaw WB, Gordon FD, McEniff NJ, et al: Severe ascites. Efficacy of the transjugular intrahepatic portosystemic shunt in treatment. Radiology 1996;200:185-192.

40 Martinet JP, Fenyves D, Legault L, et al: Treatment of refractory ascites using transjugular intrahepatic portosystemic shunt (TIPS). Dig Dis Sci 1997;42:161-166.

-41 Quiroga J, Sangro B, Nunez M, et al: Transjugular intrahepatic portal-systemic shunt in the treatment of refractory ascites: Effect on clinical, renal, humoral, and hemodynamic parameters. Hepatology 1995;21:709-716. 
-42 Peron JM, Barange K, Otal P: Transjugular intrahepatic portosystemic shunts in the treatment of refractory ascites: Results in 48 consecutive patients. J Vasc Interv Radiol 2000; 11:1211-1216.

-43 Lebrec D, Giuily N, Hadengue A, et al: Transjugular intrahepatic portosystemic shunts: Comparison with paracentesis in patients with cirrhosis and refractory ascites: A randomized trial. J Hepatol 1996;25:135-144.

-44 Ginès P, Uriz J, Calahorra B, et al: Transjugular intrahepatic portosystemic shunting versus paracentesis plus albumin for refractory ascites in cirrhosis. Gastroenterology 2002;123:18391847.
45 Rossle M, Ochs A, Gulberg V, et al: A comparison of paracentesis and transjugular intrahepatic portosystemic shunting in patients with ascites. N Engl J Med 2000;342:17011707.

46 Sanyal A, Genning C, Reddy RK, et al: The North American Study for Treatment of Refractory Ascites. Gastroenterology 2003;124: 634-641.

-47 Salerno F, Merli M, Riggio O: Randomized controlled study of TIPS versus paracentesis plus albumin in cirrhosis with severe ascites. Hepatology 2004;40:629-635.
48 Gülberg V, Liss I, Bilzer M, Waggershauser T, Reiser M, Gerbes AL: Improved quality of life in patients with refractory or recidivant ascites after insertion of transjugular intrahepatic portosystemic shunts. Digestion 2002;66:127130.

49 Chalasani N, Clark WS, Martin LG, Kamean J, Khan A, Patel N, Boyer TD: Determinants of mortality in patients with advanced cirrhosis after transjugular intrahepatic portosystemic shunting. Gastroenterology 2000;118:138144.

50 Malinchoc M, Kamath PS, Gordon FD, Peine CJ, Rank J, ter Borg PC: A model to predict poor survival in patients undergoing transjugular intrahepatic portosystemic shunts. Hepatology 2000;31:864-871. 